Revta brasil. Bot., São Paulo, V.24, n.1, p.63-72, mar. 2001

\title{
Anatomia de galhas de ambrosia em folhas de Baccharis concinna e Baccharis dracunculifolia (Asteraceae)
}

\author{
MARCOS ARDUIN ${ }^{1,3}$ e JANE ELIZABETH KRAUS ${ }^{2}$
}

(recebido: 24 de novembro de 1999; aceito: 21 de outubro de 2000)

\begin{abstract}
Anatomy of ambrosia leaf galls in Baccharis concinna and Baccharis dracunculifolia (Asteraceae)). Ambrosia galls are induced by dipteran (Cecidomyiidae) and no nutritive tissue is present: fungi hyphae are the source of food to the inducer larva. Ambrosia galls in Baccharis concinna and B. dracunculifolia have only one chamber with one inducer. The fungi hyphae are observed. In $B$. dracunculifolia galls the hyphae are restricted to the larval chamber. The parenchyma palisade cells are elongated. In $B$. concinna galls hyphae spread also among chlorenchyma cells around of larval chamber. The chlorenchyma cells near to the chamber elongate slightly. In both galls, pericyclic fibers of vascular system lose their secondary walls. When the inducer is in pupal phase, the amount of hyphae increases and they fill several parts of the larval chamber. Hyphae of $B$. concinna galls present lipophilic globules which are not observed in the hyphae of $B$. dracunculifolia galls. Picnids are found only in the senescent galls of $B$. dracunculifolia. This paper is the first contribution to the knowledge of the ambrosia galls in the Brazilian flora.
\end{abstract}

RESUMO - (Anatomia de galhas de ambrosia em folhas de Baccharis concinna e Baccharis dracunculifolia (Asteraceae)). Galhas de ambrosia são induzidas por dípteros (Cecidomyiidae) e desprovidas de tecido nutritivo, pois a larva do indutor alimenta-se de hifas de fungos. As galhas de ambrosia de Baccharis concinna e B. dracunculifolia são constituídas por uma única câmara larval, contendo um indutor. São observadas hifas de fungos. Nas galhas de $B$. dracunculifolia, as hifas ficam confinadas à câmara larval e as células do parênquima paliçádico mostram-se alongadas. Nas galhas de B. concinna, as hifas estão presentes também entre as células do clorênquima situadas ao redor da câmara larval. As células do clorênquima próximas à câmara larval alongam-se ligeiramente. As fibras pericíclicas do sistema vascular, em ambas as galhas, perdem as paredes secundárias. Quando o indutor está em fase pupal, as hifas de fungos aumentam em quantidade e preenchem várias partes da câmara larval. Nas hifas da galha de $B$. concinna verifica-se a presença de glóbulos lipofílicos, que estão ausentes nas hifas das galhas de $B$. dracunculifolia. Picnídios são observados somente nas galhas senescentes de $B$. dracunculifolia. Este trabalho é a primeira contribuição ao conhecimento de galhas de ambrosia na flora brasileira.

Key words - Baccharis dracunculifolia, Baccharis concinna, Asteraceae, ambrosia galls, anatomy

\section{Introdução}

Galhas são crescimentos especializados em tecidos vegetais, induzidos por alguns vírus, bactérias, fungos, nematóides, ácaros e insetos, que uma vez instalados obtêm alimento e abrigo. Em galhas induzidas por insetos, quando o indutor começa a se alimentar, é muito freqüente a formação do tecido nutritivo, revestindo a câmara larval. As células deste tecido geralmente apresentam citoplasma denso e nota-se o acúmulo de substâncias nutritivas (Bronner 1992). Entretanto, em algumas galhas não há formação de tecido nutritivo: os indutores alimentam-se de seiva ou, no caso das galhas de ambrosia, de hifas de fungos. Estas hifas são provenientes de

1. Universidade Federal de São Carlos, Departamento de Botânica, Rodovia Washington Luís, km 235, Bairro Monjolinho, Caixa Postal 67, 13565-905 São Carlos, SP.

2. Universidade de São Paulo, Departamento de Botânica, Rua do Matão 277, Caixa Postal 11461, 05422-970 São Paulo,SP, kraus@usp.br.

3. Autor para correspondência: darduin@ power.ufscar.br conídios, introduzidos no tecido vegetal durante a oviposição do indutor (Cecidomyiidae, Diptera) da galha (Bissett \& Borkent 1988).

O termo ambrosia, proposto por Schmidberger (1836 apud Beauverie 1910), designa um grupo de fungos que mantêm relações mutualísticas com alguns insetos (saúvas, cupins, besouros e dípteros) e alguns desses só são encontrados nestas associações (Beauverie 1910); foi Neger (1908) que empregou este termo para as galhas onde estão presentes fungos que servem de alimento para a larva do cecidomiídeo indutor ("Ambrosiagallen"). Quanto às galhas de ambrosia, ocorrem em diversas plantas (Bissett \& Borkent 1988); no gênero Baccharis, foram observadas em B. salicifolia (Mani 1964) e B. hamilifolia (Bissett \& Borkent 1988).

No Brasil, Tavares (1917) descreveu galhas em Compositae, incluindo algumas em Baccharis, e Fernandes et al. (1996) fizeram levantamento de ocorrência de galhas em espécies de Baccharis na Serra do Cipó. Esses últimos autores constataram a presença de 17 galhas em B. dracunculifolia e $14 \mathrm{em}$ $B$. concinna, mas não indicaram a presença de galhas 
de ambrosia entre elas. Entretanto, duas galhas, uma em B. concinna e outra em B. dracunculifolia, que constaram nesse levantamento são de ambrosia.

O propósito deste trabalho é fazer uma descrição morfológica e anatômica dessas galhas de ambrosia, comparando-se os aspectos estruturais e alguns histoquímicos.

\section{Material e métodos}

Foram coletadas amostras de folhas maduras com ou sem galhas, em nós distantes do ápice, em plantas de Baccharis concinna G.M. Barroso e B. dracunculifolia DC., de ambos os sexos. As amostras são provenientes de exemplares que crescem ao longo da estrada Lagoa Santa à Conceição do Mato-Dentro, na Serra do Cipó. Algumas das amostras foram herborizadas e guardadas no Herbário do Departamento de Botânica do Instituto de Biociências da USP (SPF). São elas: Baccharis dracunculifolia DC. (SPF 77102, SPF 77103, SPF 78039, SPF 78040) e Baccharis concinna G.M. Barroso (SPF 77100, SPF 77101).

Para os estudos estruturais, as amostras foram fixadas em formalina neutra tamponada (FNT), de acordo com Lillie (1948 apud Clark 1981). Para a obtenção dos cortes histológicos seriados, as amostras foram desidratadas em série etanólica crescente e processadas para inclusão em historresina à base de glicol-metacrilato (Sims 1974). Os cortes transversais e longitudinais foram corados em azul de toluidina O (C. I. 52040) a 0,25\% em bórax 1\% (Pearse 1960) diluído em água destilada (1:1, v/v) ou com azul de astra $1 \%$ e com fucsina básica (C. I. 42500) 0,05\% (Kraus et al. 1998).

Para os estudos histoquímicos, foi usado o reagente de lugol (Johansen 1940) para a detecção de amido. Para evidenciar as substâncias graxas, uma solução saturada de Sudan negro (C. I. 26150) em etanol $96^{\circ} \mathrm{GL}$ (modificado de Gahan 1984). O controle para coloração com Sudan negro foi feito com xileno (30 min) antes da coloração.

Para os estudos em microscopia eletrônica de varredura (MEV), algumas amostras de galhas foram desidratadas em série etanólica, submetidas à secagem em ponto-crítico em gás carbônico e metalizadas com ouro (Silveira 1989).

\section{Resultados}

Externamente, as galhas de $B$. concinna e $B$. dracunculifolia apresentam-se como um pequeno intumescimento, observável em ambas as faces da folha. O eixo maior da galha não tem uma orientação definida: pode ser paralelo, perpendicular ou oblíquo ao eixo maior da folha (figuras 1A, 2A). Quanto à coloração da galha, pouco se distingue da coloração da folha - apresenta-se ligeiramente mais clara quando vista contra a luz; podem também aparecer manchas escuras ou tons ligeiramente avermelhados em diversos pontos da galha, sem que obedeçam a um padrão definido. As galhas de ambrosia foram observadas desenvolvendo-se em folhas maduras.

Essas galhas contêm uma única câmara larval (figuras 1B, 2B), onde se aloja o indutor, pertencente à família Cecidomyiidae; ao emergir, ele rompe a parede da galha, podendo-se, então, notar o orifício de saída. Nas galhas das quais o indutor emergira recentemente, não foram observadas alterações significativas quanto à coloração e ao seu aspecto geral. Nas galhas senescentes, por sua vez, nota-se um halo escuro ao redor do orifício de saída e, finalmente, a destruição de parte dos tecidos epidérmicos.

As folhas das duas espécies de Baccharis possuem estrutura isobilateral e as galhas nelas formadas apresentam, basicamente, a mesma organização e distribuição dos tecidos (figuras 1B, 2B). A câmara larval situa-se no mesofilo, separando o parênquima esponjoso de um dos parênquimas paliçádicos: ou o que está próximo à superfície adaxial (figuras 1B, 2B) ou o que está próximo à abaxial; dessa forma, quando é separado o parênquima paliçádico voltado para a superfície adaxial, o parênquima esponjoso e os feixes vasculares ficam localizados sob a câmara larval; já no caso de ser separado o parênquima voltado para a face abaxial, o parênquima esponjoso e os feixes vasculares situar-se-ão acima da câmara larval. As duas situações, portanto, podem ocorrer, mas aqui, em ambas as galhas, é descrito apenas o caso em que o parênquima esponjoso fica sob a câmara.

Na galha de $B$. concinna, o tecido epidérmico permanece inalterado durante o desenvolvimento da galha, no que se refere ao tamanho das células, espessura das paredes e conteúdo protoplasmático; também não se notam alterações com relação aos estômatos e tricomas. Sobre a epiderme, inclusive na abertura de alguns estômatos e em alguns locais dentro da câmara larval, verificou-se a presença de uma substância amorfa e descontínua, que se cora em azul claro pelo azul de toluidina (figura 13); com azul de astra e fucsina básica, no entanto, ela se cora em rosa. Estes resultados indicam que se trata de uma substância basófila, mas que não reage nos testes histoquímicos realizados.

No clorênquima que circunda a região da câmara larval observa-se a presença de hifas de fungos (figuras 3,4$)$ e as células desse tecido alongam-se ligeiramente no sentido anticlinal; nota-se, também, 


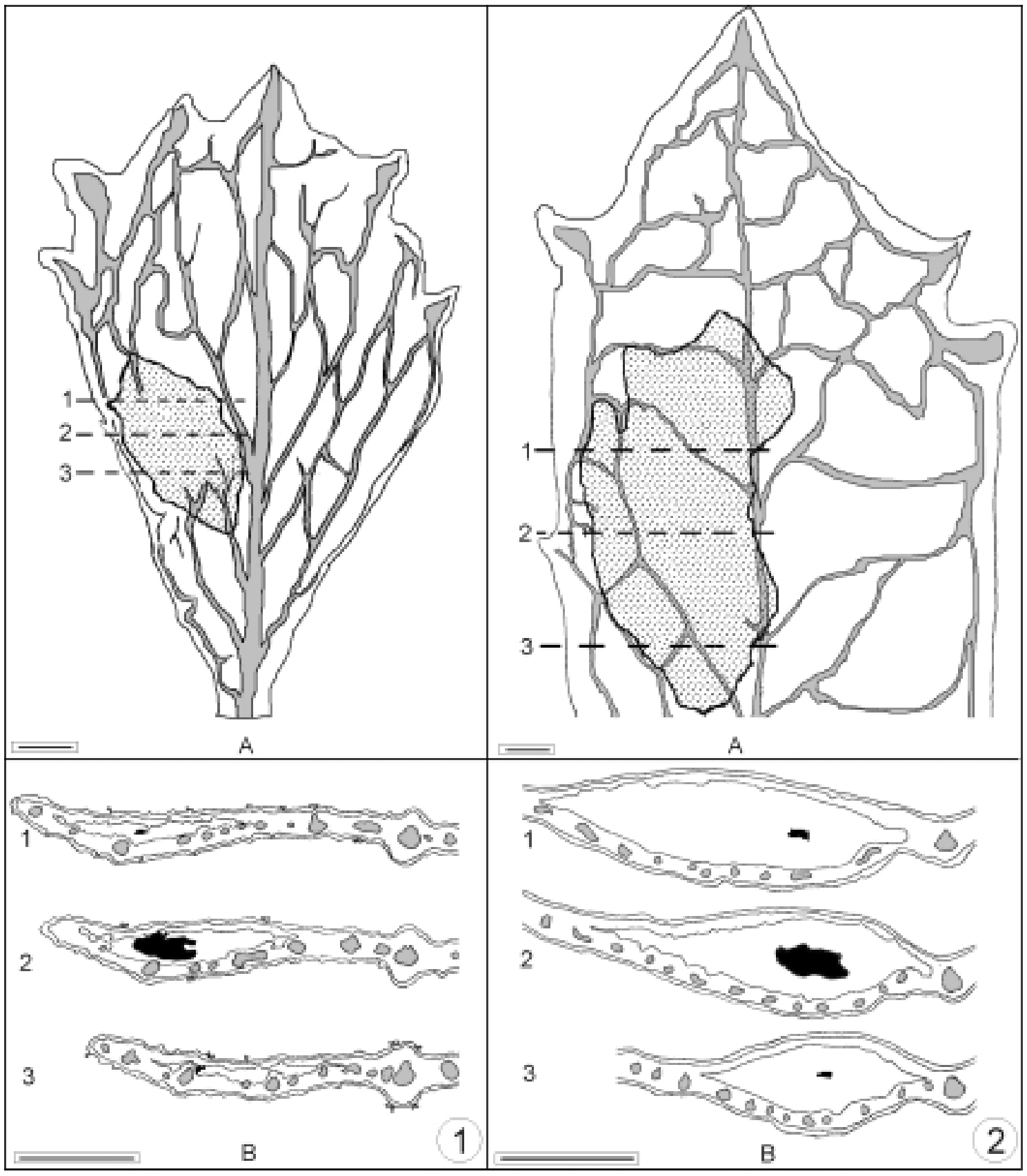

Figuras 1-2. Diagramas das galhas de ambrosia em folhas de Baccharis. 1. B. concinna. A. Vista frontal, mostrando a região onde foram realizados os cortes transversais (1-3). B. Cortes transversais. 2. B. dracunculifolia. A. Vista frontal, mostrando a região onde foram realizados os cortes transversais $(1-3)$. B. Cortes transversais. Escalas $=1 \mathrm{~mm}$. Pontilhado $=$ Galha, Cinza $=$ Sistema vascular, Preto $=$ Indutor.

uma perda de espaços intercelulares, exceto na câmara subestomática. As paredes celulares e os aspectos gerais do protoplasto são mantidos como no tecido sadio. O amido de assimilação, entretanto, visto como diminutos pontos nos cloroplastos, apresenta-se em menor quantidade. Com relação ao te- 


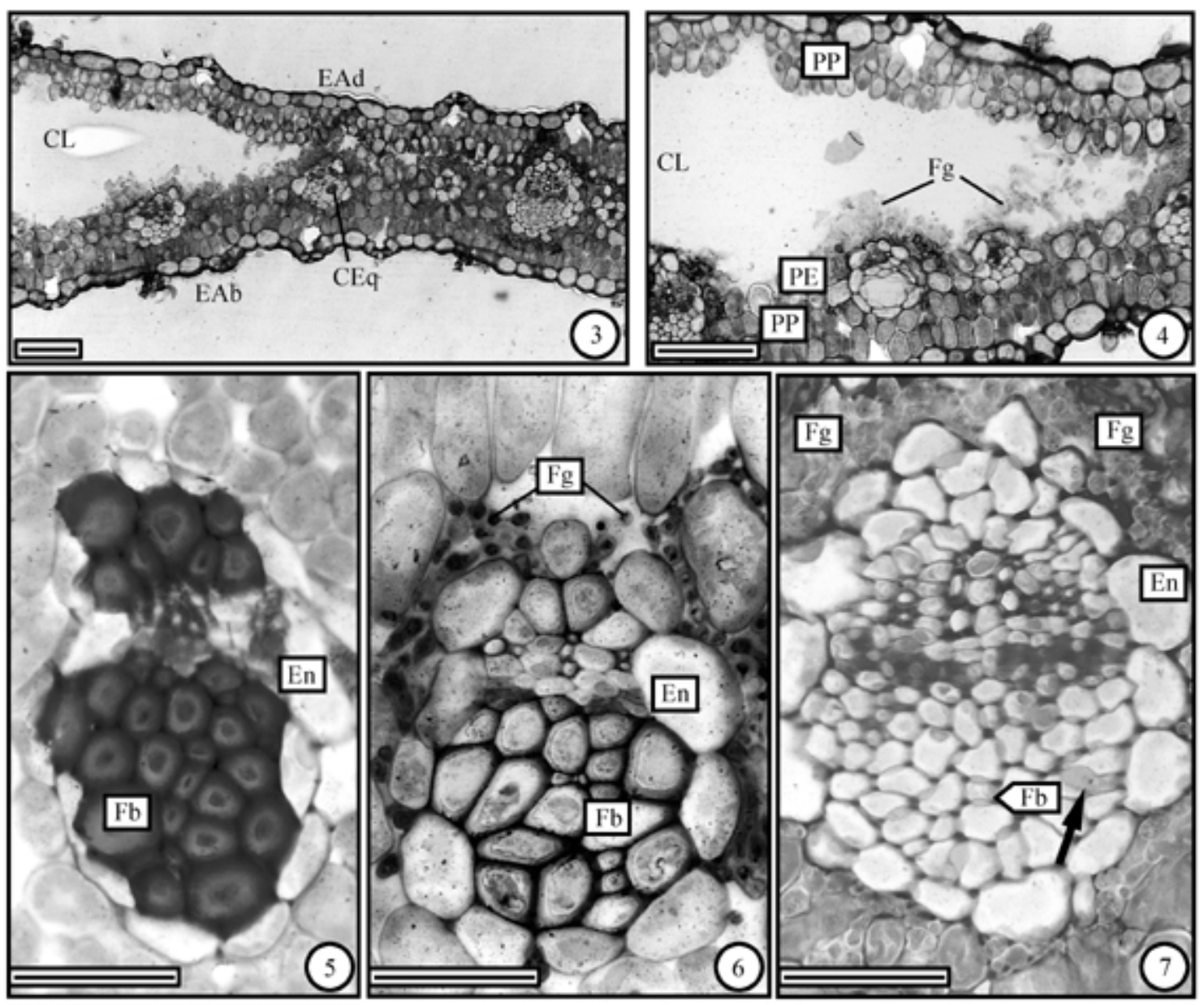

Figuras 3-7. Galha de ambrosia em folha de Baccharis concinna: cortes transversais. 3. Região da câmara larval e os tecidos adjacentes. Escala $=100 \mu \mathrm{m}$. 4. Detalhe da câmara larval. Notar a presença de fungos revestindo a câmara larval. Escala $=100 \mu \mathrm{m}$. 5-7. Detalhes dos sistemas vasculares, mostrando as modificações das fibras pericíclicas. Escalas $=50 \mu \mathrm{m}$. 5. Região afastada da câmara larval; as fibras apresentam paredes grossas, lignificadas e lume estreito. 6. Região próxima à câmara larval; as fibras mostram perda de parte da parede secundária. Notar a presença de hifas de fungos ao redor das células da endoderme. 7. Região abaixo da câmara larval; as fibras não apresentam mais paredes secundárias. Em algumas células ocorre aumento de espessura da parede primária (seta). $\mathrm{CEq}=\mathrm{Cavidade}$ esquizógena, $\mathrm{CL}=$ Câmara larval, $\mathrm{EAb}=$ Epiderme da face abaxial, EAd $=$ Epiderme da face adaxial, En $=$ Endoderme, $\mathrm{Fb}=\mathrm{Fibras}$ pericíclicas, $\mathrm{Fg}=$ Fungo, $\mathrm{PE}=$ Parênquima esponjoso, $\mathrm{PP}=$ Parênquima paliçádico.

cido secretor não se observam modificações; a figura 19 ilustra o detalhe de uma cavidade esquizógena contendo secreção lipofílica (seta). As hifas, neste estágio, revestem a câmara larval, formando uma camada fina.

Com relação ao sistema vascular, a formação da galha na folha de $B$. concinna causa alterações nas fibras pericíclicas. Estas, nos tecidos vasculares situados distantes da câmara larval (figura 5), têm as paredes secundárias espessas e o lume reduzido; próximo da câmara larval, as fibras perdem progressivamente suas paredes secundárias (figura 6). Nos tecidos vasculares situados abaixo da câmara larval, as fibras perdem totalmente as paredes secundárias (figura 7) e as paredes primárias apresentam espessamentos localizados (seta). Em ambos os casos, a endoderme, o xilema e o floema permanecem inalterados.

Passando às observações da galha de $B$. dracunculifolia, o tecido epidérmico (assim como os 
tricomas e estômatos) permanece inalterado durante todo o seu desenvolvimento; nesta galha não se notou a presença da substância amorfa sobre a epiderme, como foi observada na galha de B. concinna.

No clorênquima que circunda a câmara larval, em geral, não se observam hifas de fungos e as células do parênquima paliçádico voltado para a face adaxial alongam-se no sentido anticlinal; as células mais internas, que estão junto ao parênquima esponjoso, são as que mais se alongam (figuras 8, 9); o alongamento diminui à medida em que se afasta da câmara larval (figura 8). Comparativamente, as células do clorênquima que não se alongaram coram-se pelo azul de toluidina em tom púrpura, mais ou menos escuro, e os cloroplastos, com amido de assimilação, são evidentes (figura 14); já com relação às células alongadas, estas coram-se em tom bem mais claro e os cloroplastos são pouco numerosos ou ausentes (figura 15). As cavidades esquizógenas não se mostram alteradas. As hifas, nesse estágio, revestem a câmara larval, formando uma camada fina e os espaços intercelulares do parênquima paliçádico que revestem a câmara tendem a ser mais reduzidos, preservando-se, contudo, os da câmara subestomática (figura 9).

O sistema vascular é afetado de forma semelhante à observada na galha de $B$. concinna. Nos tecidos vasculares distantes da câmara larval (figura
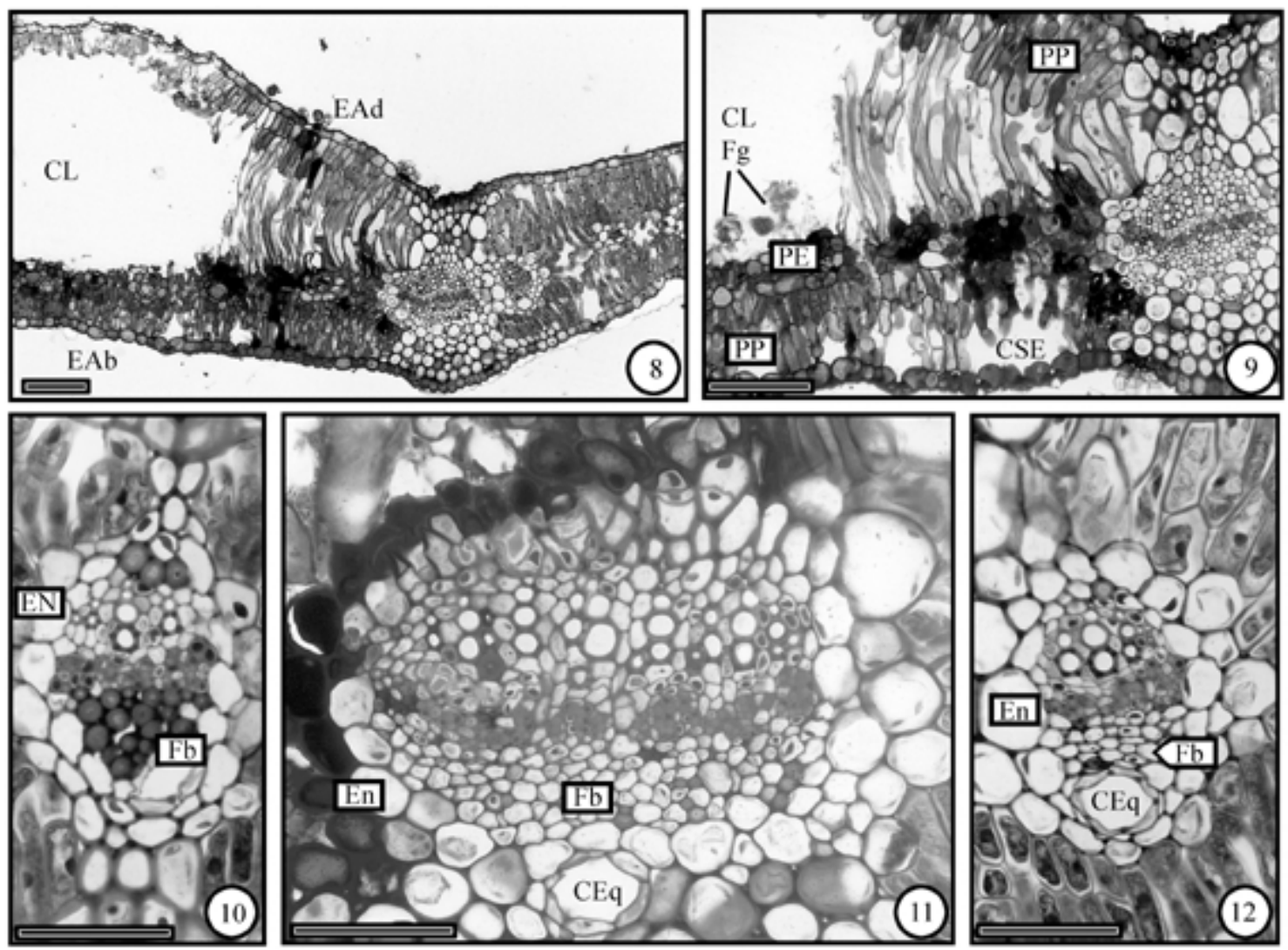

Figuras 8-12. Galha de ambrosia em folha de Baccharis dracunculifolia: cortes transversais. 8. Região da câmara larval e os tecidos adjacentes. Escala $=100 \mu \mathrm{m}$. 9. Detalhe da região da câmara larval. Notar as células alongadas do parênquima paliçádico e a presença de fungos revestindo a câmara larval. Escala $=100 \mu \mathrm{m}$. 10-12. Detalhes dos sistemas vasculares, mostrando as modificações das fibras pericíclicas. Escalas $=50 \mu \mathrm{m}$. 10. Região afastada da câmara larval; as fibras apresentam paredes grossas, lignificadas e lume estreito. 11. Região próxima à câmara larval (nervura central); as fibras mostram perda de parte da parede secundária. 12. Região abaixo da câmara larval; as fibras não apresentam mais paredes secundárias. $\mathrm{CEq}=$ Cavidade esquizógena, $\mathrm{CL}=$ Câmara larval, $\mathrm{CSE}=\mathrm{Câmara}$ Subestomática, $\mathrm{EAb}=$ Epiderme da face abaxial, $\mathrm{EAd}=$ Epiderme da face adaxial, $\mathrm{En}=$ Endoderme, $\mathrm{Fb}=$ Fibras pericíclicas, $\mathrm{Fg}=$ Fungo, $\mathrm{PE}=$ Parênquima esponjoso, $\mathrm{PP}=$ Parênquima paliçádico. 

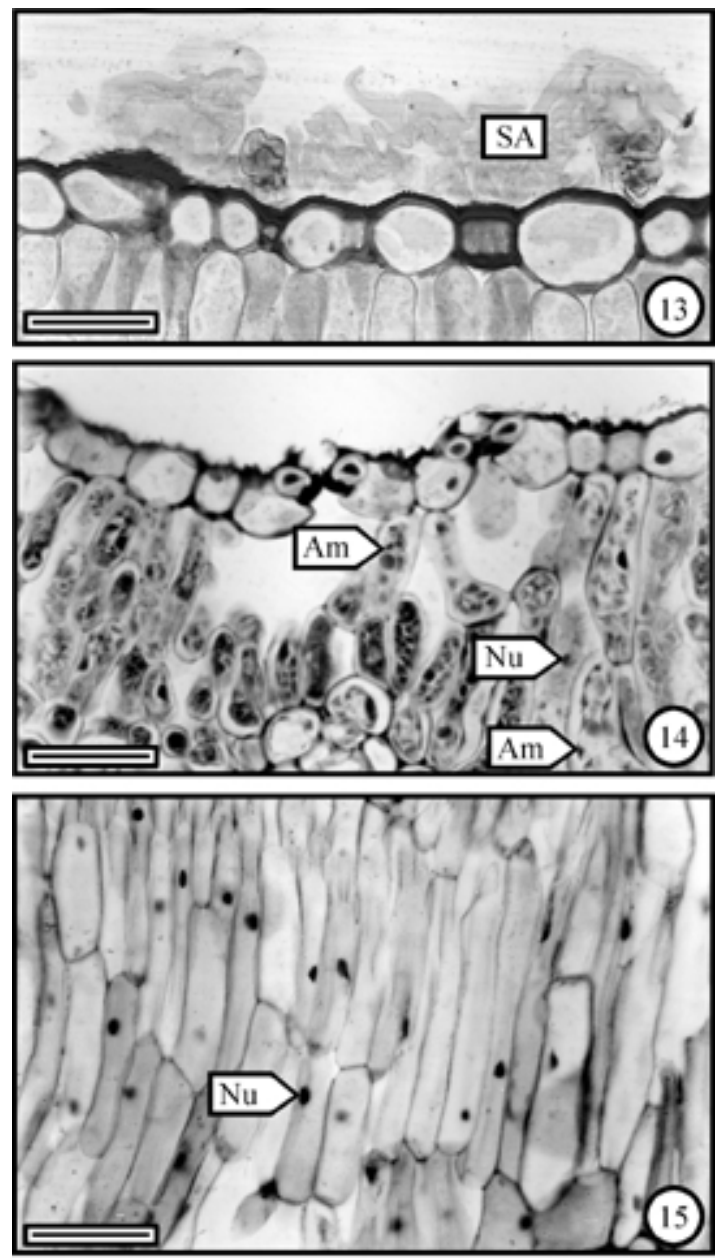

Figuras 13-15. Galhas de ambrosia em folhas de Baccharis. 13. B. concinna: notar a substância amorfa sobre a epiderme. 14-15. B. dracunculifolia. 14. Região mais afastada da câmara larval, mostrando células do parênquima paliçádico com cloroplastos contendo amido, corados por Lugol. 15. Região próxima à câmara larval, mostrando as células do parênquima paliçádico alongadas e sem cloroplastos. Escalas $=50 \mu \mathrm{m} . \mathrm{Am}=\mathrm{Amido}, \mathrm{Nu}=\mathrm{Núcleo}$, SA = Substância amorfa.

10), as fibras pericíclicas apresentam paredes secundárias espessas. Junto à câmara larval (figuras 11, 12) observa-se que essas fibras perdem progressivamente as paredes secundárias.

Em ambas as galhas, quando o indutor entra em fase pupal, deixando de se alimentar, as hifas fúngicas tendem a aumentar em quantidade e a preencher a câmara larval (figuras 16,17). Em B. concinna, as hifas se estendem por entre as células do mesofilo, crescendo por entre os espaços intercelulares ou forçando caminho entre eles (figuras 18, 19); as hifas parecem não penetrar nas células do mesofilo, mas apesar disso algumas dessas células mostram o protoplasto modificado, apresentando-se denso e escuro (figura 19, asterisco), se comparado ao das células vizinhas. Em B. concinna, são observados glóbulos lipofílicos de diversos tamanhos, dispersos por entre a massa de hifas (figura 20) que preenche a câmara larval; o material submetido ao tratamento com xileno não mostra mais tais glóbulos (figura 21). $\mathrm{Na}$ galha de $B$. dracunculifolia a massa de hifas não apresenta glóbulos lipofílicos (figura 22).

Nas galhas senescentes de ambas as espécies, alguns trechos da epiderme encontram-se invadidos por hifas do fungo, que apresentam coloração castanha-esverdeada ou ocre, sugerindo tratar-se de conídios. Na galha de $B$. dracunculifolia é observado um conidioma, do tipo picnídio (figura 23), com conídios unicelulares e blásticos. Tal estrutura não foi constatada nas galhas de B. concinna.

\section{Discussão}

Não se dispõe de registro de qualquer estudo morfológico e/ou anatômico de galhas de ambrosia na flora brasileira, como o que foi realizado em $B$. concinna e $B$. dracunculifolia.

No presente trabalho, fica evidenciado que essas galhas podem ser induzidas em tecidos maduros, pois foram vistas desenvolvendo-se em folhas que já haviam se formado há bastante tempo. Isso demonstra, portanto, que não há exigência de tecidos jovens para que os insetos possam induzir a formação dessas galhas. Segundo Rohfritsch (1992), tecidos jovens em geral são mais aptos a reagir à indução de galhas se comparados aos já diferenciados. Entretanto, isso não é uma condição exclusiva. Arduin et al. (1994) e Arduin \& Kraus (1995), por exemplo, observaram galhas de cecidomíídeos em folhas jovens e maduras de Piptadenia gonoacantha.

As galhas aqui estudadas são do tipo monotálamo, cuja câmara larval situa-se entre um dos parênquimas paliçádicos e o esponjoso, causando relativamente poucas modificações nos tecidos das plantas hospedeiras. Os tecidos da folha de $B$. concinna foram menos afetados quando comparados com os da folha de B. dracunculifolia, que apresentaram um alongamento celular mais acentuado e, 

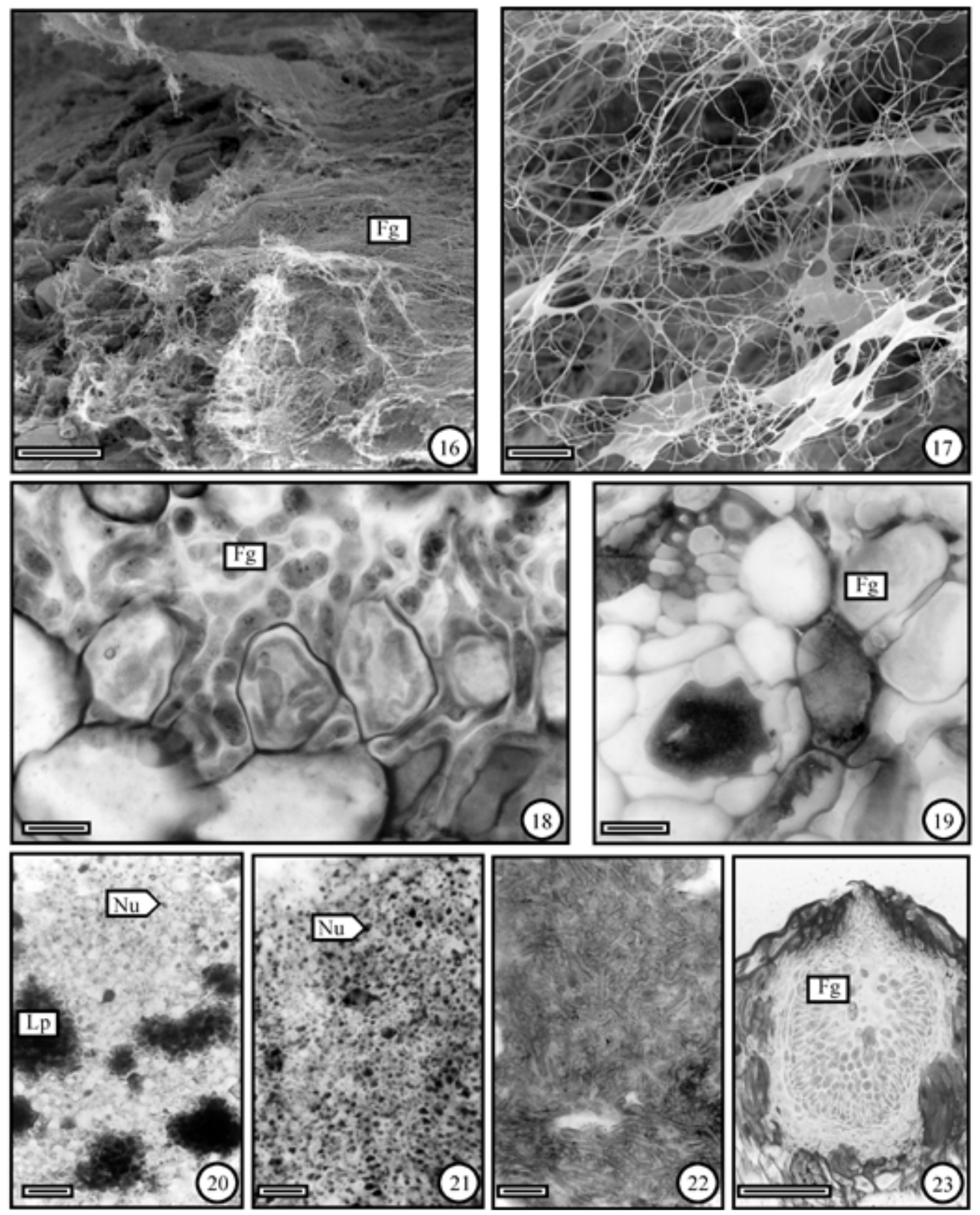

Figuras 16-23. Fungos de galhas de ambrosia em folhas de Baccharis. 16-21. B. concinna. 16. Hifas na câmara larval (MEV). Escala $=20 \mu \mathrm{m}$. 17. Detalhe das hifas (MEV). Escala $=10 \mu \mathrm{m}$. 18. Hifas crescendo entre as células do clorênquima. Escala $=10 \mu \mathrm{m}$. 19. Células do clorênquima. Notar que algumas células têm citoplasma denso e escuro (asterisco); na cavidade esquizógena acumulam-se substâncias lipofílicas (seta). Escala $=10 \mu \mathrm{m}$. 20. Hifas de fungo coradas com Sudan negro, mostrando corpos lipofílicos. Escala $=10 \mu \mathrm{m}$. 21. Os corpos lipofílicos estão ausentes após tratamento com xileno e coradas com Sudan negro. Escala = 10 $\mu \mathrm{m} .22-23$. B. dracunculifolia. 22. Hifas coradas com Sudan negro. Nestas, não há corpos lipofílicos. Escala $=10 \mu \mathrm{m}$. 23. Conidioma do tipo picnídio na galha senescente. Escala $=50 \mu \mathrm{m} . \mathrm{Fg}=$ Fungo, $\mathrm{Lp}=$ Glóbulo lipofílico, $\mathrm{Nu}=$ Núcleo. 
além disso, a ausência de cloroplastos nas proximidades da câmara larval. Nas partes mais distantes dessa, as células do clorênquima, contudo, apresentaram numerosos cloroplastos com amido de assimilação; tais resultados são semelhantes aos observados em galhas causadas pelo cecidomiídeo Asteromyia carbonifera, associados com o fungo Sclerotium asteris em Solidago graminifolia e $S$. rugosa (Camp 1981).

No trabalho citado anteriormente, o autor sugere que os cloroplastos refletem a sensibilidade ao fungo, levando à alteração no teor de amido; a redução no número e tamanho dos grãos de amido, por sua vez, sugere que o fungo induz a mobilização desta substância. O autor também afirma que há vários trabalhos que indicam a ocorrência de redução no número de cloroplastos devido à infeção pelo fungo, porém, tal ocorrência não se dá nos estágios iniciais.

De acordo com Gagné (1986), dentre os Cecidomyiidae (ordem Diptera), as tribos Lasiopterini e Asphondyliini possuem representantes que induzem galhas de ambrosia. Bissett \& Borkent (1988) indicaram que as galhas de ambrosia induzidas por insetos da tribo Asphondyliini apresentam, em geral, uma morfologia mais ou menos uniforme, característica. A fêmea perfura os tecidos jovens da planta hospedeira e introduz neles o ovo e alguns conídios; o ovo eclode em alguns dias, mas o desenvolvimento do fungo pode ser retardado por várias semanas, sendo a galha iniciada pela larva. Em sequiência, o fungo começa a se desenvolver de forma rápida, preenchendo a câmara e formando um tecido compacto, exceto imediatamente ao redor da larva, que consome o micélio e passa para os ínstares seguintes. Já com relação às galhas de ambrosia da tribo Lasiopterini, segundo Meyer (1952) e Bissett \& Borkent (1988), os estudos são menos detalhados e ficou constatada menor uniformidade estrutural e que, em geral, o micélio se desenvolve menos, não formando um tecido compacto como nas galhas de Asphondyliini.

A partir das características estruturais, bem como da pouca proliferação do micélio na câmara larval das galhas de B. concinna e B. dracunculifolia, considera-se que elas se assemelham às induzidas por insetos da tribo Lasiopterini. Bissett \& Borkent (1988), estudando a galha de B. halimifolia causada por Neolasioptera lathami, constataram também que o micélio do fungo não preenche toda a câmara larval como um tecido compacto. Nas galhas aqui estudadas, notou-se, entretanto, que quando os indutores estão no estágio de pupa e não mais se alimentam, há um aumento na quantidade de micélio, mas esse não chega a preencher toda a câmara. Portanto, conclui-se que a quantidade de micélio pode estar relacionada não só à tribo do inseto indutor, mas também à fase de desenvolvimento deste.

É importante notar que há diferenças quanto ao fungo que ocorre na galha de $B$. concinna e aquele que ocorre em $B$. dracunculifolia. Na galha de $B$. concinna, as hifas fúngicas avançam por entre as células do mesofilo na região ao redor da câmara larval e, quando se forma a massa das mesmas na câmara larval, ela apresenta glóbulos lipídicos. Nas galhas de B. dracunculifolia as hifas ficam restritas à própria câmara e, quando se forma a massa de hifas, ela não apresenta os glóbulos; e, finalmente, nas galhas senescentes desta espécie era comum a presença de conidiomas do tipo picnídio, que não foram verificados nas de $B$. concinna.

Ross (1914 apud Meyer \& Maresquelle 1983) também ilustrou a presença de picnídios em galha de Asphondylia rosmarini em Rosmarinus officinalis; Borkent \& Bissett (1985 apud Bissett \& Borkent 1988) apontam que o fungo presente nas galhas de ambrosia pertence ao gênero Macrophoma (Ascomycetes) e salientam, ainda, que muitas espécies de cecidomiídeos indutores utilizam-se de uma mesma espécie de fungo. Entretanto, os conidiomas do tipo picnídio são característicos de fungos Coelomycetes, pertencentes aos fungos Mitospóricos, anteriormente chamados Deuteromycetes. Salienta-se, assim, a necessidade de estudos mais amplos no que se refere à identificação dos fungos que ocorrem em galhas.

As observações deste trabalho, quanto ao micélio, mostram que esse apresenta crescimento intercelular. Vários autores, como Meyer (1952, 1987), Camp (1981) e Meyer \& Maresquelle (1983), relataram a mesma situação.

Um fenômeno comum às duas galhas foi a perda de parede secundária das fibras pericíclicas; embora haja fungos capazes de sintetizar lignases, esse não é o caso observado nas galhas de ambrosia, uma vez que o xilema permanece intacto. A perda das paredes 
secundárias, entretanto, parece ser um evento freqüente em galhas que se desenvolvem em plantas cujas fibras pericíclicas são vivas. Resultados similares foram observados em galhas desenvolvidas por cecidomiídeos em Struthanthus vulgaris (Arduin et al. 1991), em Piptadenia gonoacantha (Arduin \& Kraus 1995) e em Ficus microcarpa (Souza et al. 2000), o que permite concluir que a perda da parede secundária das fibras pericíclicas não é um fenômeno exclusivo das galhas de ambrosia.

Os indutores das galhas de ambrosia observadas em $B$. concinna e $B$. dracunculifolia pertencem à família Cecidomyiidae (Diptera) (Fernandes et al. 1996), porém ainda não há uma identificação em nível de espécie para os mesmos. Nesse mesmo trabalho, os autores indicam um inseto do gênero Geraldesia como indutor da galha que ocorre em $B$. dracunculifolia. Bronner (1992), por sua vez, indica apenas quatro gêneros nos quais ocorrem representantes de indutores de galhas de ambrosia: Kiefferia, Asphondylia, Schizomyia e Lasioptera.

Diversos autores apontam a importância das galhas de ambrosia por fornecerem subsídios para a elaboração de modelos evolutivos, através dos quais se busca interpretar a forma como o hábito galhador teria surgido na família Cecidomyiidae. Muitos cecidomiídeos são micetófagos, como por exemplo, todos os representantes da subfamília Lestremiinae e as tribos Oligotrophini e Cecidomyiini da subfamília Cecidomyiinae; já as tribos Lasiopterini e Asphondyliini possuem representantes que, embora sejam galhadores, alimentam-se de fungos que crescem em suas câmaras larvais, ou seja, são endomicetófagos. Bissett \& Borkent (1988) consideram a endomicetofagia como caráter plesiomórfico, argumentando que foi a partir dele que surgiu o hábito endofitófago, de acordo com o qual o inseto passa a se alimentar do tecido vegetal e não há mais a ocorrência de fungos.

Finalizando, as interações de fungos de ambrosia com formigas, besouros ou térmites constituem modelos de estudos ecológicos interessantes. As galhas de ambrosia tornam-se um exemplo ainda mais atraente pelo fato de mostrarem uma interação mais complexa, uma vez que incluem também alterações no tecido vegetal, o que não é amplamente observado nas outras interações. Assim, este trabalho com $B$. concinna e $B$. dracunculifolia representa uma contribuição para o estudo desta interessante interação que envolve planta hospedeira, um inseto indutor e um fungo do qual ele se alimenta.

Agradecimentos - M. Arduin agradece ao CNPq e à Capes a bolsa de pós-graduação concedida e J.E. Kraus ao CNPq (Proc. 30.1776/83) e à FAPESP (Proc. 1997/0493-2). Os autores agradecem à Dra Rosely Grandi, do Instituto de Botânica, as informações relacionadas aos fungos.

\section{Referências bibliográficas}

ARDUIN, M., KRAUS, J.E. \& VENTURELLI, M. 1991. Estudo morfológico de galha achatada em folha de Struthanthus vulgaris Mart. (Loranthaceae). Revista Brasileira de Botânica 14:147-156.

ARDUIN, M., KRAUS, J.E. \& MONTENEGRO, G. 1994. Morfologia e fenologia de galhas foliares de Piptadenia gonoacantha (Fabales, Mimosaceae). Revista Brasileira de Entomologia 38:79-89.

ARDUIN, M. \& KRAUS, J.E. 1995. Anatomia e ontogenia de galhas foliares de Piptadenia gonoacantha (Fabales, Mimosaceae). Boletim de Botânica da Universidade de São Paulo 14:109-130.

BEAUVERIE, J. 1910. Les champignons dits ambrosia. Annales des Sciences Naturalles, série Botanique 11:31-73.

BISSETT, J. \& BORKENT, A. 1988. Ambrosia galls: the significance of fungal nutrition in the evolution of the Cecidomyiidae (Diptera). In Coevolution of fungi with plants and animals. (K.A. Pirozynski \& D.L. Hawksworth, eds.). Academic Press, London, p.203-205.

BRONNER, R. 1992. The role of nutritive cells in the nutrition of cynipids and cecidomyiids. In Biology of insect-induced galls. (J.D. Shorthouse \& O. Rohfritsch, eds.). Oxford University Press, Oxford, p. 118-140.

CAMP, R.R. 1981. Insect-fungus blister galls on Solidago graminifolia and S. rugosa. I. A macroscopic and light microscopic study of the host-parasite relationship. Canadian Journal of Botany 59:2466-2477.

CLARK, G. 1981. Staining procedures. Williams \& Wilkins, Baltimore.

FERNANDES, G.W., CARNEIRO, M.A.A., LARA, A.C.F., ALLAIN, L.R., ANDRADE, G.I., JULIÃO, G.R., REIS, T.R. \& SILVA, I.M. 1996. Galling insects on neotropical species of Baccharis (Asteraceae). Tropical Zoology 9:315-332.

GAGNÉ, R.J. 1986. The transition from fungus-feeding to plant-feeding in Cecidomyiidae (Diptera). Proceedings of the Entomological Society of Washington 88:381-384.

GAHAN, P.B. 1984. Plant histochemistry and citochemistry. Academic Press, London.

JOHANSEN, D. A. 1940. Plant microtechnique. McGraw-Hill, New York.

KRAUS, J.E., SOUSA, H.C., REZENDE, M.H., CASTRO, N.M., VECHI, C. \& LUQUE, R. 1998. Astrablue and basic fuchsin double staining of plant materials. Biotechnic \& Histochemistry 73:235-243.

MANI, M.S. 1964. Ecology of plant galls. Dr. Junk Publisher, The Hague. 
MEYER, J. 1952. Cécidogenèse de la galle de Lasioptera rubi Heeger et rôle nourricier d'un mycélium symbiotique. Comptes Rendus (hebdomadaires) de L'Académie des Sciences 234:2556-2558.

MEYER, J. 1987. Plant galls and gall inducers. Gerbrüder Borntraeger, Berlin.

MEYER, J. \& MARESQUELLE, H.J. 1983. Anatomie des galles. Gebrüder Borntraeger, Berlin.

NEGER, F.W. 1908. Ambrosiapilze. Berichte der Deutschen Botanischen Gesellschaft 26:735-754.

PEARSE, A.G.E. 1960. Histochemistry, theoretical and applied. 2 ed., J. \& A. Churchill Ltd., London.

ROHFRITSCH, O. 1992. Patterns in gall development. In Biology of insect-induced galls. (J.D. Shorthouse \& O. Rohfritsch, eds.). Oxford University Press, Oxford, p.60-86.
SILVEIRA, M. 1989. Preparo de amostras biológicas para microscopia eletrônica de varredura. In Manual sobre técnicas básicas em microscopia eletrônica. v 1. (W. Souza, ed.). Sociedade Brasileira de Microscopia Eletrônica, Rio de Janeiro, p.71-79.

SIMS, B. 1974. A simple method of preparing 1-2 $\mu \mathrm{m}$ sections of large tissue blocks using glycol methacrylate. Journal of Microscopy 101:223-227.

SOUZA, S.C.P.M., KRAUS, J.E., ISAÍAS, R.M. \& NEVES, L.J. 2000. Anatomical and ultrastructural aspects of leaf galls in Ficus microcarpa L. f. (Moraceae) induced by Gynaikothrips ficorum Marchal (Thysanoptera). Acta Botanica Brasilica 14:57-69.

TAVARES, J.S. 1917. Cecídias brazileiras que se criam em plantas das famílias das Compositae, Rubiaceae, Tiliaceae, Lythraceae e Artocarpaceae. Brotéria, Série Zoológica 15:113-183. 